Franco Laghi

Rafael Fernandez

\section{Erratum to: Noninvasive ventilation for weaning in hypoxemic respiratory failure: not ready for prime time}

Published online: 6 November 2012

(C) Springer-Verlag Berlin Heidelberg and ESICM 2012

The online version of the original article can be found under doi:10.1007/s00134-012-2680-3.

\section{F. Laghi $(\bowtie)$}

Division of Pulmonary and Critical Care Medicine,

Edward Hines, Jr. Veterans Affairs Hospital,

$111 \mathrm{~N}, 5$ th Avenue and Roosevelt Road,

Hines, IL 60141, USA

e-mail: flaghi@lumc.edu

Tel.: +1-708-2022705

Fax: +1-708-2027907

F. Laghi

Edward Hines, Jr. Veterans Affairs Hospital,

Loyola University, Stritch School of Medicine,

Maywood, IL, USA

\section{R. Fernandez}

Intensive Care Unit, Hospital Sant Joan de,

Deu-Fundacio Althaia, Manresa, Spain

R. Fernandez

Universitat Internacional de Catalunya,

Sant Cugat del Valles, Spain

R. Fernandez

CIBERES Group 33, Sabadell, Spain

\section{Erratum to: Intensive Care Med (2012) 38:1583-1585 DOI 10.1007/s00134-012-2680-3}

Two affiliations of the co-author Rafael Fernandez were not included in the manuscript supplied for publication. The complete and correct affiliations are given here. 